\title{
Endoscopic retrograde cholangiopancreatography (ERCP) in critically ill patients is safe and effective when performed in the endoscopy suite
}

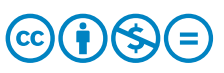

\author{
Authors \\ Domenico A. Farina, Srinadh Komanduri, A. Aziz Aadam, Rajesh N. Keswani
}

Institution

Northwestern University, Department of Gastroenterology and Hepatology, Chicago, Illinois, United States

submitted 25.7.2019

accepted after revision $\quad 12.2 .2020$

Bibliography

DOI https://doi.org/10.1055/a-1194-4049 |

Endoscopy International Open 2020; 08: E1165-E1172

(c) Georg Thieme Verlag KG Stuttgart · New York eISSN 2196-9736

\section{Corresponding author}

Domenico A. Farina, MD, Northwestern University, Department of Gastroenterology and Hepatology, $676 \mathrm{~N}$ St. Clair St. , Arkes Pavilion Suite 1400, Chicago, IL 60611 Fax: +1-312-695-3999

domenico.farina@northwestern.edu

Supplementary material

Online content viewable at:

https://doi.org/10.1055/a-1194-4049

\section{ABSTRACT}

Background and study aims Critically ill patients may require endoscopic retrograde cholangiopancreatography (ERCP) but performing ERCP in the intensive care unit
(ICU) poses logistic and technical challenges. There are no data on ICU patients undergoing ERCP in the endoscopy suite. The primary aim of this study was to report outcomes, including safety, when ERCP in critically ill patients is performed in the endoscopy suite.

Patients and methods We queried our institutional endoscopy database to identify all ICU patients who underwent ERCP at a single academic medical center from 04/01/ 2010 to $11 / 30 / 2017$. Only patients admitted to an ICU prior to ERCP were included.

Results Of 7,218 ERCPs performed during the study period, 260 ERCPs (3.6\%) were performed in 231 ICU patients (mean age 61y; 53\% male); nearly all ICU patient ERCPs $(n=258$; 99\%) occurred in the endoscopy suite. ERCP indications included cholangitis (50\%), post-liver transplant cholestasis (15\%), and bile leak (10\%). All ERCPs were performed with anesthesiology, most with general anesthesia $(60 \%)$ and in the prone position (60\%). Most patients $(73 \%)$ had sepsis. Prior to ERCP, $17 \%$ of patients required vasopressors; vasopressors were begun during ERCP in $4 \%$.

The cannulation success rate was $95 \%$ (94\% in native papillae). Adverse events occurred in $9 \%(n=23)$ of cases with post-ERCP pancreatitis most common. No patients died during or within 24 hours of ERCP. Mortality at 30 days was $16 \%$, all attributed to underlying disease.

Conclusions When advanced ventilatory and hemodynamic support is available, critically ill patients can safely and effectively undergo ERCP in the endoscopy suite.

\section{Introduction}

Endoscopic retrograde cholangiopancreatography (ERCP) is essential to diagnosis and therapy of pancreaticobiliary disease [1-7]. However, ERCP requires resources and expertise beyond that of standard gastrointestinal endoscopy, including the need for high-quality fluoroscopy, special equipment, experienced nurses, and endoscopists with expertise in ERCP [5,8-10]. These needs create logistical challenges when performing emergent ERCP in patients with pancreaticobiliary diseases and critical illness requiring intensive care unit (ICU) care [5, $10,11]$. However, despite the logistical challenges, ERCP remains first-line treatment for a myriad of diseases that may lead to sepsis and ICU care [2, 4, 12-16].

To avoid transporting critically ill patients out of the ICU, ERCP is often performed at the bedside in critically ill patients $[4,5,10,17-19]$. However, performing an ERCP in the ICU may be challenging due to substandard fluoroscopy, limited avail- 
ability of equipment, disruptions to endoscopy schedule, and limited physical space $[1,10,19,20]$. There is no standard of care for performing ERCP in critically ill patients based on the limited data published on this patient population $[4,5,10,17-$ 19]. Of those data, all prior studies that have examined the safety and outcomes of ERCP in ICU patients have looked at the procedure performed at the bedside or in operating rooms $[4,5,10,17-19]$. Our institutional practice is for all patients undergoing ERCP to have the procedure performed in the endoscopy suite. There are no published data on outcomes and safety of performing ERCP in critically ill patients in the endoscopy suite $[11,18,19]$. As no standard of care exists, the primary aims of this study were to report the technical success and safety of ERCP in critically ill patients performed in the endoscopy suite.

\section{Patients and methods Study design and patients}

We queried our institutional endoscopy database to identify all patients who underwent ERCP at our single academic medical center during the study period (March 2010 to November 2017). The electronic health record (EHR) was then reviewed to determine which patients were admitted to the ICU at the time of ERCP. We excluded patients younger than 18 years of age. Patients were also excluded if they were not critically ill at the time ERCP was begun, but later required admission to the ICU, including patients that were transferred directly to an ICU from the endoscopy suite due to intra-procedural concerns. A waiver of informed consent was approved by the institutional review board (IRB) of Northwestern University.

\section{Data collection}

After identifying patients appropriate for study inclusion, we used the EHR to abstract relevant patient and procedure data. Patient-level data collected included age, gender, race, ethnicity, body mass index (BMI), medical comorbidities, tobacco use, alcohol use history, history of prior ERCPs, and history of prior sphincterotomy. Procedure data abstracted included procedure indications, whether deep cannulation of the duct of interest was successful, maneuvers performed (e.g., sphincterotomy, balloon dilation, stent removal or stent placement), overall procedure success, procedure duration and fluoroscopy time (when available), whether endoscopic ultrasound (EUS) was also performed, and adverse event (AE) rates. We also collected details on type of ICU admission (e.g., medical versus surgical ICU), length of stay (ICU and overall), and time from admission to ERCP. Peri-procedural and intra-procedural variables from the anesthesia record were abstracted including vasopressor medications used, type of anesthesia, patient positioning, airway monitoring, and hemodynamic data; hemodynamic data collected included vital signs, number of systemic inflammatory response syndrome (SIRS) criteria present at time of ERCP, respiratory status, and use of vasopressors in the ICU. Finally, medical outcomes data were collected including serum bilirubin levels, respiratory failure requiring mechanical ventilation, kidney injury with or without need for continuous veno-venous hemodialysis (CVVH), presence of comorbid infections, blood culture results, adverse events, and mortality (within 24 hours, within 30 days, and within 60 days).

\section{Definitions}

Patients were defined as critically ill if they were admitted to an ICU at the time of ERCP or had been evaluated and accepted by an ICU prior to ERCP $[2,3,12]$. We categorized our ICUs as the medical ICU, neuro-spine ICU, coronary care unit, surgical ICU and cardiothoracic/transplant ICU. These ICUs are located on the seventh, eighth, and ninth floors across two connected pavilions that make up our medical center. The endoscopy suites are located on the fourth floor of one pavilion, requiring critically ill patients to travel via elevator. Successful ERCP was defined as cannulation of the duct of interest and completion of needed pancreaticobiliary therapy, regardless of patient outcome. Shock was defined as need for vasopressor support [3, 21]. Institutional policy at our center is for all patients on vasopressors to have an arterial line inserted including prior to transfer out of the ICU to the endoscopy suite. Sepsis was defined as meeting two or more systemic inflammatory response syndrome (SIRS) criteria with suspicion for infection or explicit documentation of sepsis by the ICU team in the EHR [3]. Length of ICU stay was defined as time from admission to an ICU to transfer to a hospital floor, death or discharge. Timing of ERCP was calculated as time from admission to an ICU to arrival in the endoscopy suite. Procedure time was calculated from the documented time of initial anesthesia induction in the endoscopy suite to the documented time of termination of anesthesia support as specified in the procedure report. This was done in lieu of endoscope insertion and withdrawal time as the anesthesia procedure time reflected the time of patients under anesthesia support.

\section{Statistical analysis}

Descriptive statistics were reported using means and standard deviations or interquartile ranges, when appropriate, for continuous variables and proportions for categorical variables. Student's $t$-test was used for continuous variables while a Pearson's chi-squared test was used for categorical variables. All tests were two-sided. The level of statistical analysis significance was set at $P<0.05$.

\section{Results}

\section{Study population}

We identified 7,218 ERCPs performed in 3,822 patients ( $\triangleright$ Fig. 1) over the study period. Of these ERCPs, 260 ERCPs (3.6\%) were performed in 231 critically ill patients admitted to an ICU. Nearly all ERCPs ( $\mathrm{n}=258$; $99.2 \%)$ performed in ICU patients were performed in the endoscopy suite; these 258 ERCPs in 231 patients comprised our study cohort. Just two ERCPs were performed bedside in an ICU setting with biliary stenting due to multi-vasopressor shock and impending cardiovascular arrest and were excluded from our analysis. 


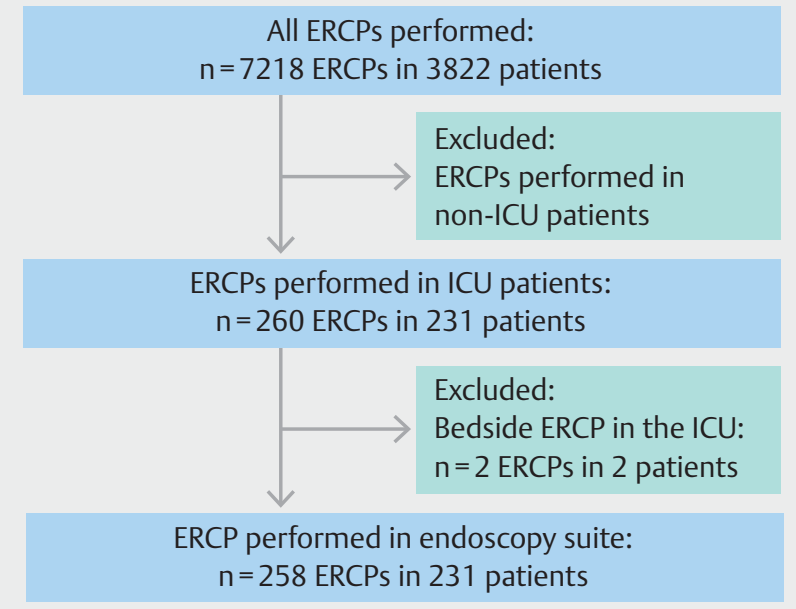

Fig. 1 Study population. There were 7218 ERCPs performed in 3822 patients, following exclusion criteria, 258 ERCPs in $231 \mathrm{pa}-$ tients were examined.

\section{Patient characteristics}

The mean age of ICU patients undergoing ERCP was 61 years (range: 18 to 94; $>$ Table 1) with a mean BMI of 28.0 (SD 6.5). In total, $42.2 \%$ of patients had comorbid malignancy including hepatocellular carcinoma (7.4\%), cholangiocarcinoma (6.5\%), and pancreas malignancy (6.1\%). Approximately one-fourth of patients had previously undergone liver transplantation. A majority of patients $(n=135,52.3 \%)$ had previously undergone ERCP. Medical comorbidities were common including hypertension (50.2\%), cirrhosis (39.4\%), type II diabetes mellitus (33.3\%) and chronic kidney disease (22.5\%). Most ERCPs occurred in patients admitted to the medical ICU (52.3\%) followed by the cardiothoracic-transplant ICU (33.7\%). Mean duration of ICU admission was 13.2 days (range: 0.5 to 92 ) and mean duration of hospital stay was 21.4 days (range 1.5 to 151;

\section{- Table 2).}

The majority (73.2\%) of ICU patients undergoing ERCP in the endoscopy suite had clinical sepsis at time of ERCP and $152 \mathrm{pa}$ tients $(58.9 \%)$ met two or more SIRS criteria ( $\bullet$ Table 2$)$. Acute kidney injury (AKI) was present in $55.8 \%$ of patients, including $26(10.1 \%)$ who required CVVH at the time of their ERCP. Many critically ill patients had concurrent infections including pneumonia $(n=30,11.6 \%)$, urinary tract infection $(n=18,7.0 \%)$, peritonitis $(n=17,6.6 \%)$, and cholecystitis $(n=15,5.8 \%$; $>$ Table 2).

\section{ERCP indications and outcomes}

Of the 258 ERCPs performed in the endoscopy suite, the most common primary indications were cholangitis ( $n=129,50.0 \%$ ), post-liver transplant cholestasis $(n=39,15.1 \%)$, bile leak $(n=$ 26, $10.1 \%)$ and malignant obstruction ( $n=21,8.1 \%$; Table 3 ). Patient positioning was determined collaboratively between endoscopist and anesthesia provider. More than half the ERCPs $(n=154,59.7 \%)$ were performed in the prone/semi-prone position, while just 53 cases (20.5\%) were performed in the supine
- Table 1 Patient demographic information, medical history and comorbid conditions, and type of ICU admission.

\begin{tabular}{|c|c|c|}
\hline & $\mathbf{n}$ & (\%) \\
\hline Total patients & 231 & $(100.0 \%)$ \\
\hline \multicolumn{3}{|l|}{ Gender } \\
\hline - Male & 122 & $(52.8 \%)$ \\
\hline - Female & 109 & $(47.2 \%)$ \\
\hline Mean age in years (range) & \multicolumn{2}{|c|}{$60.7(18-94)$} \\
\hline Mean BMI (range) & \multicolumn{2}{|c|}{$28(14.9-61.3)$} \\
\hline \multicolumn{3}{|l|}{ Race/ethnicity } \\
\hline - Caucasian & 132 & $(57.1 \%)$ \\
\hline - African American & 39 & $(16.9 \%)$ \\
\hline - Hispanic & 20 & $(8.7 \%)$ \\
\hline - Asian & 13 & $(5.6 \%)$ \\
\hline - Other & 15 & $(6.5 \%)$ \\
\hline - Declined/Unknown & 12 & $(5.2 \%)$ \\
\hline \multicolumn{3}{|l|}{ Comorbid malignancy } \\
\hline - Hepatocellular carcinoma & 17 & $(7.4 \%)$ \\
\hline - Cholangiocarcinoma/gallbladder cancer & 15 & $(6.5 \%)$ \\
\hline - Pancreatic cancer & 14 & $(6.1 \%)$ \\
\hline - Other cancer & 37 & $(16.0 \%)$ \\
\hline Had prior ERCP & 135 & $(52.3 \%)$ \\
\hline Prior liver transplant (OLT) & 66 & $(28.6 \%)$ \\
\hline \multicolumn{3}{|l|}{ Comorbidities } \\
\hline - Hypertension & 116 & $(50.2 \%)$ \\
\hline - Diabetes Type II & 77 & $(33.3 \%)$ \\
\hline - Cirrhosis & 91 & $(39.4 \%)$ \\
\hline - CKD & 52 & $(22.5 \%)$ \\
\hline - CAD & 50 & $(21.6 \%)$ \\
\hline - Stroke & 24 & $(10.4 \%)$ \\
\hline \multicolumn{3}{|l|}{ Patient ICU location } \\
\hline - Medical ICU & 135 & $(52.3 \%)$ \\
\hline - Cardiac Care Unit & 3 & $(1.2 \%)$ \\
\hline - Surgical ICU & 31 & $(12.0 \%)$ \\
\hline - Cardiothoracic/Thoracic ICU & 87 & $(33.7 \%)$ \\
\hline - Neuro-spine ICU & 2 & $(0.8 \%)$ \\
\hline
\end{tabular}

CKD, chronic kidney disease; CAD, coronary artery disease; BMI, body mass index; OLT, orthotopic liver transplant.

position ( $\bullet$ Table 3 ). In 85 cases (32.9\%), a sphincterotomy had previously been performed. Deep cannulation of the duct of interest was successful in $95.0 \%(n=245)$ of all cases and $93.6 \%$ of cases with native papillae. There were just 13 cases (6.4\%) of 
- Table 2 ICU characteristics, duration of hospital stays, sepsis criteria and co-morbid ICU conditions.

\begin{tabular}{|c|c|c|}
\hline & (n) & (\%) \\
\hline Total ERCPs & 258 & $(100.0 \%)$ \\
\hline $\begin{array}{l}\text { Mean time to ERCP from ICU Admission in } \\
\text { days (range) }\end{array}$ & \multicolumn{2}{|c|}{$5.3(0.1-67)$} \\
\hline \multicolumn{3}{|l|}{ Acute Kidney Injury (AKI) at time of ERCP } \\
\hline - No AKI & 114 & $(44.2 \%)$ \\
\hline - AKI not on CVVH & 118 & $(45.7 \%)$ \\
\hline - AKI on CVVH & 26 & $(10.1 \%)$ \\
\hline Clinical sepsis at time of ERCP & 189 & $(73.2 \%)$ \\
\hline \multicolumn{3}{|l|}{ SIRS criteria at time of ERCP } \\
\hline - 0 of 4 & 42 & $(16.3 \%)$ \\
\hline - 1 of 4 & 64 & $(24.8 \%)$ \\
\hline - 2 of 4 & 70 & $(27.1 \%)$ \\
\hline - 3 of 4 & 55 & $(21.3 \%)$ \\
\hline - 4 of 4 & 27 & $(10.5 \%)$ \\
\hline Systolic blood pressure $<100$ at start of ERCP & 74 & $(28.7 \%)$ \\
\hline \multicolumn{3}{|l|}{ Concurrent infections } \\
\hline - Pneumonia & 30 & $(11.6 \%)$ \\
\hline - Urinary tract infection & 18 & $(7.0 \%)$ \\
\hline - Peritonitis & 17 & $(6.6 \%)$ \\
\hline - Wound/cellulitis & 2 & $(0.8 \%)$ \\
\hline - Cholecystitis & 15 & $(5.8 \%)$ \\
\hline - Clostridium difficile & 4 & $(1.6 \%)$ \\
\hline - Other & 8 & $(3.1 \%)$ \\
\hline - Multiple concurrent infections & 10 & $(3.9 \%)$ \\
\hline - Bacteremia with positive blood cultures & 97 & $(37.6 \%)$ \\
\hline Mean duration of ICU stay in days (range) & \multicolumn{2}{|c|}{$13.2(0.5-92)$} \\
\hline $\begin{array}{l}\text { Mean duration of hospitalization in days } \\
\text { (range) }\end{array}$ & \multicolumn{2}{|c|}{$21.4(1.5-151)$} \\
\hline \multicolumn{3}{|c|}{$\begin{array}{l}\text { SIRS, systemic inflammatory response syndrome; four criteria: } \\
\text { 1) temperature }>38^{\circ} \mathrm{C} \text { or }<36^{\circ} \mathrm{C} \text {; } \\
\text { 2) white blood cell count }>12,000 \text { cells } / \mathrm{mm}^{3} \text { or }<4000 \text { cells } / \mathrm{mm}^{3} \text {; } \\
\text { 3) respiratory rate }>0 \text { breaths } / \text { minute; } \\
\text { 4) heart rate }>90 \text { beats } / \text { minute } \\
\mathrm{CVVH} \text {, continuous veno-venous hemodialysis }\end{array}$} \\
\hline
\end{tabular}

ERCP failure (Supplementary Table 1). Four occurred in patients with cholangitis, all of whom went for percutaneous drainage. Six failures were secondary to obstruction or stenosis of the duodenum. Two of those cases were in the setting of pseudocyst from pancreatitis and the patients underwent cystogastrostomy, which relieved extrinsic compression to allow repeat ERCP attempt. In 26 cases (10.1\%), EUS was performed at the same time as ERCP with common bile duct stone evaluation as the most common indication $(n=13)$ followed by evalua- tion and management of peri-pancreatic fistulae and fluid collections $(n=11)$. Median time from ICU admission/acceptance to performance of ERCP was 1.5 days (Interquartile Range: 0.7, 4.9; Table 2).

Biliary or pancreatic stents were placed during 168 ERCPs (65.1\%). Of the 129 cases of cholangitis, 63 ERCPs (48.8\%) showed retained biliary stone(s) at time of procedure. Complete removal of stones was achieved in $81 \%(51 / 63)$ of choledocholithiasis cases. In the remaining cases (12/63, $19 \%)$, there was biliary stent placement. A biliary or pancreatic sphincterotomy was performed in 64 cases (24.8\%; > Table 3 ). Two ERCPs performed in critically ill patients with walled off necrosis also underwent concurrent necrosectomy. Mean fluoroscopy time was 14.9 minutes ( $n=42$, range: 1.9 to 50.7$)$. Mean procedure time was 50.2 minutes ( $n=180$, range: 12 to 163 ). Mean procedure time did not differ between patients undergoing ERCP in the prone/semi-prone position compared to those in the supine position $(60.0 \pm 50.1 \mathrm{~min}$ vs $68.3 \pm 44.9 \mathrm{~min}, P=0.5)$.

Approximately one-fifth of patients underwent repeat ERCP during the same hospital admission. The most common indication for it was stent exchange or stent removal (38/55, 69.1\%). Just $10.9 \%(6 / 55)$ of repeat ERCPs were performed due to unsuccessful initial ERCP. Among patients with baseline jaundice, there was an improvement in mean serum bilirubin pre-ERCP to 72 hours post-ERCP $(9.1 \mathrm{mg} / \mathrm{dL}$ vs $6.9 \mathrm{mg} / \mathrm{dL}, P=0.02$; $>$ Table 3). Among the 189 patients with clinical sepsis at time of ERCP, $71.4 \%$ recovered and were subsequently transferred out of the ICU $(n=135)$. In terms of clinical success of ERCP for patients in shock, 57 patients $(22.1 \%)$ remained on vasopressors at the end of their ERCP and $75.4 \%$ ultimately recovered and were weaned off all vasopressors ( $n=43$, > Fig. 2 ). In the acute setting, $22.8 \%(13 / 57)$ of patients in shock were weaned from vasopressors in less than 24 hours.

\section{Anesthesia and cardiopulmonary support for ERCP}

All procedures were performed with anesthesiology assistance (typically a certified registered nurse anesthetist with on-site attending anesthesiologist supervision) and choice of anesthesia support was determined by the respective anesthesia provider. Most ERCPs were performed with general anesthesia ( $n=$ 154, 59.7\%; - Table 4). More than half the patients under general anesthesia ( $n=88 ; 57.1 \%$ ) were intubated in the endoscopy suite immediately prior to the procedure. Of 88 patients intubated in the endoscopy suite for their ERCP, 27 remained intubated and were transferred back to the ICU on a ventilator (10.5\% of all cases). The majority of patients transferred back to an ICU after intubation for ERCP remained intubated for more than 24 hours $(18 / 27,66.7 \%)$. Five patients (1.9\%) were intubated during ERCP due to hemodynamic or respiratory instability.

Overall, 44 patients (17.1\%) required vasopressor support for hypotension at time of transfer to the endoscopy suite for ERCP ( $>$ Table 4). The majority (75.0\%) of patients on vasopressors underwent ERCP for acute cholangitis. Of the 44 patients requiring vasopressors at the start of their ERCP, 25 (56.8\%) experienced worsening hypotension requiring increased vasopressor support. An additional 10 patients (3.9\%) were started 
- Table 3 Indication for ERCP, procedural details, serum bilirubin levels, technical success, complications and mortality.

\begin{tabular}{|c|c|c|}
\hline & $\mathbf{n}$ & (\%) \\
\hline Total ERCPs & 258 & $(100 \%)$ \\
\hline Prior sphincterotomy at time of ERCP & 85 & $(32.9 \%)$ \\
\hline \multicolumn{3}{|l|}{ ERCP procedural details } \\
\hline - Stents placed & 168 & $(65.1 \%)$ \\
\hline - Stents removed & 75 & $(29.1 \%)$ \\
\hline - Pancreatic duct cannulated/injected & 60 & $(23.3 \%)$ \\
\hline - Occlusion cholangiogram performed & 53 & $(20.5 \%)$ \\
\hline - Balloon dilation & 40 & $(15.5 \%)$ \\
\hline - Sphincterotomy performed & 64 & $(24.8 \%)$ \\
\hline - Necrosectomy & 2 & $(0.8 \%)$ \\
\hline - Complete biliary stone removal & $51 / 63$ & $(81.0 \%)$ \\
\hline - Brushings taken & 8 & $(3.1 \%)$ \\
\hline Endoscopic ultrasound performed & 26 & $(10.1 \%)$ \\
\hline \multicolumn{3}{|l|}{ Endoscopic ultrasound indication } \\
\hline - Biliary stone evaluation & 13 & $(5.0 \%)$ \\
\hline - Peri-pancreatic fluid collection/fistula & 11 & $(4.3 \%)$ \\
\hline - Other & 2 & $(0.8 \%)$ \\
\hline Mean fluoroscopy time in minutes (range) & \multicolumn{2}{|c|}{$14.9(1.9-50.7)$} \\
\hline Mean procedure time in minutes (range) & \multicolumn{2}{|c|}{$50.2(12-163)$} \\
\hline \multicolumn{3}{|l|}{ Indication for ERCP } \\
\hline - Cholangitis & 129 & $(50.0 \%)$ \\
\hline - Malignant obstruction & 21 & $(8.1 \%)$ \\
\hline - Bile leak & 26 & $(10.1 \%)$ \\
\hline - Post-liver transplant cholestasis & 39 & $(15.1 \%)$ \\
\hline - Hemobilia & 10 & $(3.9 \%)$ \\
\hline $\begin{array}{l}\text { - Other cholestatic liver injury } \\
\text { (jaundice) }\end{array}$ & 11 & $(4.3 \%)$ \\
\hline - Gallstone pancreatitis & 15 & $(5.8 \%)$ \\
\hline - Pancreatic fistula & 7 & $(2.7 \%)$ \\
\hline
\end{tabular}

Technical success (cannulation of duct of interest)

\begin{tabular}{|l|c|c|}
\hline - All ERCPs & 245 & $(95.0 \%)$ \\
\hline - ERCPs with native papillae & $162 / 173$ & $(93.6 \%)$ \\
\hline Pre-ERCP serum bilirubin in mg/dL (range) & \multicolumn{2}{|c|}{$9.1(0.3-61.8)$} \\
\hline Post-ERCP serum bilirubin in mg/dL (range) & \multicolumn{2}{|c|}{$6.9(0.1-62.1)$} \\
\hline ERCP adverse events & 23 & $(8.9 \%)$ \\
\hline - Post-sphincterotomy bleed & 3 & $(1.2 \%)$ \\
\hline - Post-ERCP Pancreatitis & 12 & $(4.7 \%)$ \\
\hline - Bile leak & 1 & $(0.4 \%)$ \\
\hline - Intubated within 24 hours post ERCP & 6 & $(2.3 \%)$ \\
\hline - Liver subcapsular hematoma & 1 & $(0.4 \%)$ \\
\hline
\end{tabular}

- Table 3 (Continuation)

\begin{tabular}{|l|c|c|}
\hline & $\mathbf{n}$ & $\mathbf{( \% )}$ \\
\hline - Duodenal wall mucosal injury & 1 & $(0.4 \%)$ \\
\hline - Aspiration pneumonia & 1 & $(0.4 \%)$ \\
\hline Mortality post-ERCP & & \\
\hline - Deceased within 24 hours of ERCP & 0 & $(0 \%)$ \\
\hline - Deceased within 30 days of ERCP & 40 & $(15.5 \%)$ \\
\hline - Deceased within 60 days of ERCP & 61 & $(23.6 \%)$ \\
\hline Repeat ERCP required during admission & 47 & $(18.2 \%)$ \\
\hline ERCP, endoscopic retrograde cholangiopancreatography & \\
\hline
\end{tabular}

\begin{tabular}{|c|c|c|c|}
\hline \multirow[b]{2}{*}{$\begin{array}{l}\text { On vaso- } \\
\text { pressors } \\
\text { prior to ERCP } \\
\mathrm{n}=44\end{array}$} & $\vec{~}$ & $\begin{array}{l}\text { Increased vaso- } \\
\text { pressor dose } \\
\text { during } \mathrm{ERCP} n=15\end{array}$ & \multirow[b]{2}{*}{$\begin{array}{l}\text { On vaso- } \\
\text { pressors } \\
\text { from the } \\
\text { endoscopy } \\
\text { suite } n=51\end{array}$} \\
\hline & \multicolumn{2}{|c|}{$\begin{array}{l}\text { Additional vaso- } \\
\text { pressor agent } \\
\text { added during } \\
\text { ERCP } \mathrm{n}=10\end{array}$} & \\
\hline & $\rightarrow$ & $\begin{array}{l}\text { Vasopressor } \\
\text { weaned off during } \\
\text { ERCP } n=3\end{array}$ & \multirow{2}{*}{$\begin{array}{l}\text { Started on } \\
\text { vasopressors } \\
\text { immediately } \\
\text { post ERCP } \\
n=6\end{array}$} \\
\hline & & $\begin{array}{l}\text { Started on vaso- } \\
\text { pressors during } \\
\text { ERCP } n=10\end{array}$ & \\
\hline
\end{tabular}

- Fig. 2 Vasopressor support was required in 44 patients at the start of ERCP, and changed during ERCP and immediately following ERCP in the ICU.

on vasopressors during their ERCP. A small number of patients ( $n=6,2.3 \%$ ) who were not on vasopressors before or during their ERCP developed shock after their ERCP and were started on vasopressor support immediately on arrival to the ICU from the endoscopy suite. Of the 51 patients who ultimately returned to the ICU, 19 patients (37.3\%) died within 30 days of their ERCP.

\section{Adverse events and mortality}

AEs occurred in $8.9 \%(n=23)$ of cases with post-ERCP pancreatitis being most frequent $(n=10,3.9 \%$; $>$ Table 3$)$. Two patients $(0.8 \%)$ experienced both post-sphincterotomy bleeding and post-ERCP pancreatitis. One additional patient $(0.4 \%)$ experienced post-sphincterotomy bleeding alone following ERCP. Six patients required intubation within 1 day of ERCP. No patients died during or within 24 hours of ERCP. Mortality at 30 days was $15.5 \%$ and at 60 days was $23.6 \%$. The most common cause of 30 -day mortality was malignancy $(11 / 40,27.5 \%)$, followed by 
- Table4 Anesthesia type, patient positioning, ventilatory support, and vasopressor support.

\begin{tabular}{|c|c|c|}
\hline & $\mathbf{n}$ & $(\%)$ \\
\hline Total ERCPs & 258 & $(100.0 \%)$ \\
\hline \multicolumn{3}{|l|}{ Anesthesia for ERCP } \\
\hline - Monitored anesthesia care (MAC) & 99 & $(38.4 \%)$ \\
\hline - General anesthesia & 154 & $(59.7 \%)$ \\
\hline - MAC converted to general anesthesia & 5 & $(1.9 \%)$ \\
\hline \multicolumn{3}{|l|}{ Positioning for ERCP } \\
\hline - Prone/semi-prone & 154 & $(59.7 \%)$ \\
\hline - Supine & 53 & $(20.5 \%)$ \\
\hline - Not stated & 51 & $(19.8 \%)$ \\
\hline \multicolumn{3}{|l|}{ Ventilatory support in peri-ERCP setting } \\
\hline - Intubated in endoscopy suite for ERCP & 88 & $(34.1 \%)$ \\
\hline $\begin{array}{l}\text { - Intubated for ERCP and brought to ICU } \\
\text { on ventilator }\end{array}$ & 27 & $(10.5 \%)$ \\
\hline - Intubated in ICU prior to ERCP & 83 & $(32.2 \%)$ \\
\hline - Extubated in ICU within 24 hours of ERCP & 27 & $(10.5 \%)$ \\
\hline \multicolumn{3}{|l|}{ Vasopressor support in peri-ERCP period } \\
\hline $\begin{array}{l}\text { - Requiring vasopressors in ICU prior to } \\
\text { ERCP }\end{array}$ & 44 & $(17.1 \%)$ \\
\hline - Vasopressor dose increased during ERCP & $15 / 44$ & $(34.1 \%)$ \\
\hline $\begin{array}{l}\text { - Additional vasopressor agent added } \\
\text { during ERCP }\end{array}$ & $10 / 44$ & $(22.7 \%)$ \\
\hline - Vasopressors stopped during ERCP & 3 & $(1.2 \%)$ \\
\hline - Vasopressors begun during ERCP & 10 & $(3.9 \%)$ \\
\hline $\begin{array}{l}\text { - Vasopressors started on arrival to ICU } \\
\text { from ERCP }\end{array}$ & 6 & $(2.3 \%)$ \\
\hline $\begin{array}{l}\text { - Vasopressor support weaned }<24 \text { hours } \\
\text { post-ERCP }\end{array}$ & $13 / 57$ & $(22.8 \%)$ \\
\hline
\end{tabular}

ERCP, endoscopic retrograde cholangiopancreatography; ICU, intensive care unit

septic shock (10/40, 25\%), and respiratory failure (8/40, $20 \%$; Supplementary Table 2).

\section{Discussion}

Pancreaticobiliary disease is a common cause or result of critical illness requiring ICU care in both medical and surgical patients. However, there is little data regarding the technical success and safety of ERCP performed in critically ill patients [10, 15, 17-19]. Moreover, there are no published data on performing ERCP in critically ill patients in the endoscopy suite. In this study of critically ill patients (73\% with sepsis at time of ERCP and $17 \%$ on vasopressors prior to ERCP) undergoing ERCP in an endoscopy suite, we found a high technical success rate (overall cannulation success rates of $95 \%$ ) with no peri-procedural mortality and low morbidity. Thus, the data in this study confirm that ERCP, when performed by expert endoscopists, in critically ill patients is both safe and effective in the endoscopy suite.

There are few studies reporting outcomes of ERCP in critically ill patients. Most studies have examined timing of ERCP and resulting effects on patient outcomes, typically acute cholangitis or gallstone pancreatitis $[5,9,13,14,17,20,22,23]$. Most studies have been small case series focused on bedside ERCPs in the intensive care unit and had much smaller cohorts $[5,10$, $11,19,20]$. Saleem et al. reported a biliary cannulation success rate of $92 \%$ in their cohort of 22 critically ill patients and a 30 day mortality of $55 \%$ [10]. In a study by Ramirez et al., ERCPs in ICU patients were performed in an "emergency radiology department" and they reported a biliary cannulation success rate of $87 \%$ in their cohort of 32 critically ill patients and a 30-day mortality of $25 \%$ [19]. Lekharaju et al. looked at emergency ERCP (performed within 6 to 8 hours of developing an indication) in 33 critically ill patients requiring inotropic and/or mechanical ventilator support who were deemed too unstable to undergo ERCP in the endoscopy suite [18]. Procedures were performed in emergency operating rooms with mobile C-arm fluoroscopy and full anesthesia assistance [18]. They showed a biliary cannulation success rate of $100 \%$, but six patients died within 24 hours with a 30-day mortality was $25 \%$ [18].

In our study, which included significantly more patients, nearly all (95\%) ERCPs were technically successful (defined as successful cannulation of the desired duct); the native papillae cannulation success rate was $93.6 \%$. This observed cannulation success rate in our population of critically ill patients is in excess of the guideline-recommended minimum cannulation success rates in the literature for non-critically ill patients [24]. Moreover, our cannulation success rate exceeded smaller studies in the literature regarding bedside ERCP $[10,20]$. Despite critical illness, the vast majority of cases were performed in the prone or semi-prone position. A large proportion of our patients were in shock on vasopressors at the time of transfer to the endoscopy suite and the majority of those patients experienced resolution of shock following ERCP. It is notable that, despite the critically ill nature of the patients, no patients suffered cardiac arrest or death during ERCP in the endoscopy suite. However, not surprisingly given the patient population, $15.5 \%$ of patients died within 30 days of undergoing ERCP. No deaths in our study were attributed directly to either the ERCP itself or being transported out of the ICU to undergo ERCP. Also notable was the relatively low rate of $A E s$, the most common being post-ERCP pancreatitis. The observed $8.9 \% \mathrm{AE}$ rate in our critically ill patient population appears to be comparable to the rates of $5 \%$ to $10 \%$ observed in the literature for non-critically ill patients $[1,22,25,26]$.

There are a variety of possible advantages to performing ERCP in the endoscopy suite including higher procedure success rates $[5,10,18]$. For example, a majority of patients in the current study underwent ERCP in the prone/semi-prone position, which would not be possible in an ICU hospital bed [10, $18,19]$. Prior studies highlight the logistical difficulties of performing ERCP in ICU hospital beds, particularly the incompatibility with mobile fluoroscopy units $[10,19,20]$. In adddition, performing the procedure in the endoscopy suite allows for uti- 
lization of fixed fluoroscopy, improving the quality of cholangiograms, which is vital for select indications (e.g., pancreaticobiliary leaks or post-transplant strictures) $[5,10,18,20]$. In contrast, bedside ERCP often leads to empiric stent placement to achieve biliary decompression given imaging limitations [ 10 , 19,20]. Moreover, by performing ERCPs in the endoscopy suite, a variety of other therapeutic and diagnostic techniques can be applied to achieve the best long-term result. Patients in this study were able to undergo EUS, necrosectomy, and fluoroscopic nasoenteric tube placement. Lastly, institutions may choose to perform ERCPs in critically ill patients in operating rooms (OR) with anesthesia. However, this often leads to logistical problems and conflicts with prior OR scheduling, in addition to the associated increased costs with performing advanced endoscopic procedures in the $O R$ as opposed to the endoscopy suite [27]. In contrast, there may be advantages to ERCPs performed at the bedside in the ICU including avoiding the difficulty in transport critically ill patients, minimizing the need to navigate and manage multiple complex intravenous lines, especially given newer fluoroscopy compatible hospital beds, and no additional need for both anesthesia and respiratory support $[10,18,28,29]$. However, in our large study, we showed no AEs associated with transporting a patient from an ICU to undergo ERCP in the endoscopy suite, including the $17 \%$ of patients in shock at the time of transport.

There are limitations to this study. The design was retrospective, which has inherent limitations. First, all ERCPs were performed by experienced ERCP endoscopists, all of whom perform in excess of 300 ERCPs annually. These findings may not be generalizable to less experienced endoscopists. Our inpatient endoscopy suites also have full anesthesia support from nurse and attending anesthesiologists capable of handling ventilated patients, which may not generalizable to other facilities despite a national trend to increasing anesthesia support in endoscopy [30]. In addition, it is unclear what percentage of patients were deemed "too unstable" for ERCP and were referred for percutaneous drainage. Due to our practice patterns, this study lacks a comparator group of patients who underwent bedside ERCP. Finally, a definite estimation of AEs is challenging as many patients were intubated and sedated. Thus, some patients may have developed unrecognized post-ERCP pancreatitis which could have contributed to patient morbidity.

\section{Conclusion}

In conclusion, critically ill patients can safely and effectively undergo ERCP in the endoscopy suite. While the vast majority of cases are technically successful, care providers must be prepared to provide advanced hemodynamic support.

\section{Competing interests}

Dr. Komanduri is a consultant for Medtronic, Boston Scientific, Cook Medical, Olympus Corp, and GI Suppl and has received educational grants from Boston Scientific. Dr. Aadam is a consultant for Boston Scientific. Dr. Keswani is a consultant for Boston Scientific and Medtronic

\section{References}

[1] Silviera ML, Seamon MJ, Porshinsky B et al. Complications related to endoscopic retrograde cholangiopancreatography: a comprehensive clinical review. Journal of gastrointestinal and liver diseases: JGLD 2009; 18: 73-82

[2] Kinney TP. Management of ascending cholangitis. Gastrointest Endosc Clin North Am 2007; 17: 289-306, vi

[3] Dellinger RP, Levy MM, Rhodes A et al. Surviving sepsis campaign: international guidelines for management of severe sepsis and septic shock: 2012. Crit Care Med 2013; 41: 580-637

[4] Coelho-Prabhu N, Shah ND, Van Houten H et al. Endoscopic retrograde cholangiopancreatography: utilisation and outcomes in a 10 year population-based cohort. BMJ Open 2013: 3

[5] Siegel JH, Rodriquez R, Cohen SA et al. Endoscopic management of cholangitis: critical review of an alternative technique and report of a large series. The Am J Gastroenterol 1994; 89: 1142-1146

[6] Maple JT, Ikenberry SO, Anderson MA et al. The role of endoscopy in the management of choledocholithiasis. Gastrointest Endosc 2011; 74: 731-744

[7] Mosler P. Diagnosis and management of acute cholangitis. Current gastroenterology reports 2011; 13: 166-172

[8] Baillie J. ERCP from soup to nuts: evaluation, preparation, execution, and follow-up. In: Lee LS. ERCP and EUS: A Case-Based Approach. New York, NY: Springer New York; 2015: 57-76

[9] Chak A, Cooper GS, Lloyd LE et al. Effectiveness of ERCP in cholangitis: a community-based study. Gastrointest Endosc 2000; 52: 484-489

[10] Saleem A, Gostout C], Petersen BT et al. Outcome of emergency ERCP in the intensive care unit. Endoscopy 2011; 43: 549-551

[11] Britton E, Bhalme M, Martin DF et al. Sa1501 An Audit of ERCP in the intensive care unit (ICU) setting at a tertiary referral centre. Gastrointest Endosc 2011; 73: AB190

[12] Attasaranya S, Fogel EL, Lehman GA. Choledocholithiasis, ascending cholangitis, and gallstone pancreatitis. Med Clin North Am 2008; 92 : 925-960, $x$

[13] Fogel EL, Sherman S. ERCP for gallstone pancreatitis. N Engl ] Med 2014; $370: 1956$

[14] Hou LA, Laine L, Motamedi N et al. Optimal timing of endoscopic retrograde cholangiopancreatography in acute cholangitis. J Clin Gastroenterol 2017; 51: 534-538

[15] Magalhaes ], Rosa B, Cotter J. Endoscopic retrograde cholangiopancreatography for suspected choledocholithiasis: From guidelines to clinical practice. World J Gastrointest Endosc 2015; 7: 128-134

[16] Frakes JT. Biliary pancreatitis: a review. Emphasizing appropriate endoscopic intervention. J Clin Gastroenterol 1999; 28: 97-109

[17] Yuan S, Sun DY. Application of bedside emergency ERCP in the treatment of severe acute biliary pancreatitis. World Chinese J Digest 2013; 21: 2217-2220

[18] Lekharaju VPK, Iqbal J, Noorullah O et al. Emergency endoscopic retrograde cholangiopancreatography in critically ill patients is a safe and effective procedure. Frontline Gastroenterol 2013; 4: 138-142

[19] Ramirez FC, McIntosh AS, Dennert B et al. Emergency endoscopic retrograde cholangiopancreatography in critically ill patients. Gastrointest Endosc 1998; 47: 368-371

[20] Shah R, Qayed E. Bedside Endoscopic retrograde cholangiopancreatography using portable $x$-ray in acute severe cholangitis. Case Rep Gastrointest Med 2018; 2018: 3

[21] Bonanno FG. Clinical pathology of the shock syndromes. J Emerg Trauma Shock 2011; 4: 233-243 
[22] Vandervoort J, Soetikno RM, Tham TCK et al. Risk factors for complications after performance of ERCP. Gastrointest Endosc 2002; 56: 652-656

[23] Khashab MA, Tariq A, Tariq U et al. Delayed and unsuccessful endoscopic retrograde cholangiopancreatography are associated with worse outcomes in patients with acute cholangitis. Clin Gastroenterol Hepatol 2012; 10: 1157-1161

[24] Peng C, Nietert P], Cotton PB et al. Predicting native papilla biliary cannulation success using a multinational Endoscopic Retrograde Cholangiopancreatography (ERCP) Quality Network. BMC Gastroenterol 2013; 13: 147

[25] Suissa A, Yassin K, Lavy A et al. Outcome and early complications of ERCP: a prospective single center study. Hepatogastroenterology 2005; 52: 352-355
[26] Chandrasekhara V, Khashab MA, Muthusamy VR et al. Adverse events associated with ERCP. Gastrointest Endosc 2017; 85: 32-47

[27] Phillips MT, Al-Shoha M, Tharian B. Tu1044 Advanced Endoscopy in the endoscopy lab vs. operating room: a cost and outcome analysis. Gastrointest Endosc 2017; 85: AB552

[28] Nalbandi V, Natse T, lasonidou $C$ et al. Experience with continuous venovenous hemofiltration $(\mathrm{CVVH})$ in the ICU: a report from a single center. Critical Care 2001; 5: P213

[29] Joannidis M. Continuous renal replacement therapy in sepsis and multisystem organ failure. Seminars Dialysis 2009; 22: 160-164

[30] Lin OS, Weigel W. Nonoperating room anesthesia for gastrointestinal endoscopic procedures. Curr Opin Anaesthesiol 2018; 31: 486-491 